\title{
STUDY OF ASPHALT-CONCRETE PAVEMENT FATIGUE MODELING
}

\author{
PETERIS SKELS ${ }^{1 *}$, VIKTORS HARITONOVS ${ }^{2}$, \\ PAVEL AKISHIN ${ }^{3}$, ANDRIS FREIMANIS ${ }^{4}$ \\ ${ }^{1,2,4}$ Dept. of Roads and Bridges, Faculty of Civil Engineering, \\ Riga Technical University, Riga, Latvia \\ ${ }^{3}$ Institute of Materials and Structures, Faculty of Civil Engineering, \\ Riga Technical University, Riga, Latvia
}

Received 11 December 2019; accepted 24 January 2020

\begin{abstract}
Deterioration of asphalt pavements due to fatigue cracking is one of the most common highway pavement failure types. If the fatigue cracks are allowed to develop and grow, the driving comfort and safety, i.e., serviceability of the pavement, decreases. Pavement fatigue behaviour is not a straightforward mechanism and involves many factors and effects, thus computational methods are developed in order to help understand how the pavement works. This paper explores the accuracy and applicability of a less computational resource demanding procedure that uses transient material mechanical behaviour to model the long-term behaviour of a pavement structure. First, the mechanical and fatigue properties of asphalt were determined at the laboratory. Then a four-layer finite-element model was created using Ansys software. Two different models - with and without infinity elements - and two different fatigue simulation procedures - full and simplified - were considered. Material parameters were obtained by the
\end{abstract}

* Corresponding author. E-mail: peteris.skels_1@rtu.lv

Viktors HARITONOVS (ORCID ID 0000-0003-3119-2677)

Andris FREIMANIS (ORCID ID 0000-0003-4654-2625)

Peteris SKELS (ORCID ID 0000-0002-1337-5114)

Pavel AKISHIN (ORCID ID 0000-0002-9074-4673)

Copyright (C) 2021 The Author(s). Published by RTU Press

This is an Open Access article distributed under the terms of the Creative Commons Attribution License (http://creativecommons.org/licenses/by/4.0/), which permits unrestricted use,

distribution, and reproduction in any medium, provided the original author and source are credited. 
laboratory tests and material properties degraded over time. Cyclic surface loading was applied to simulate the passing of a truck - 6 million fatigue cycles were simulated.

Keywords: asphalt, fatigue, finite element analysis, pavement, structural health monitoring.

\section{Introduction}

Deterioration of asphalt pavements due to fatigue cracking is one of the most common highway pavement failure types. Fatigue damage is caused by repeated traffic loading that creates a series of connected cracks. They initiate at the bottom of the asphalt layer and then grow to the surface and in the longitudinal direction. Initially, the cracks are thin and sparsely distributed, but if further development is allowed the longitudinal cracks connect and many separate asphalt prisms form. Moreover, the formed cracks allow moisture to infiltrate in the road structure, which leads to an even faster deterioration. Passing vehicles can pull out these asphalt prisms from the pavement or they break down completely. In either case, a pothole in the road pavement forms, which reduces the driving comfort by increasing the noise level, decreases safety by reducing tire friction and making the pavement surface more uneven, which may also increase the costs of vehicle maintenance Vanelstraete \& Francken (2014).

Computational modelling is commonly used to reduce the number of required experiments and thus reduce costs. Several different approaches have been used by researchers to model road structures. Kutay, Chatti and Lei (2011) developed the layered viscoelastic algorithm to model flexible pavements based on quasi-elastic theory proposed by Schapery (1969), (1974). Zaghloul and White (1993) used a three-dimensional FE model to investigate pavement response to moving loads. They employed a visco-elastic material model for AC, extended Dricker-Prager model for the granular road base and Calm Clay model for the soils in the subgrade (Zaghloul, 1993). Kim (2000) showed that Drucker-Prager plasticity model is not suitable to model nonlinear unbound layers, and adopted Uzan model for the granular materials and cohesive soils with the Mohr-Coulomb failure criterion in the nonlinear FE analysis. Erlingsson (2002) used a linear elastic model in a three-dimensional FE analysis of low volume road pavements. Elseifi, Al-Qadi, and Yoo (2006) compared viscoelastic and elastic models and found that viscoelastic constitutive models increase accuracy. Yin, Stoffels, and Solaimanian (2008) used viscoelastic 3D FE model that showed a reasonable prediction
Study

of Asphalt-Concrete Pavement Fatigue Modeling 
of strain response in the field. Onyango (2009) used nonlinear creep models to model permanent deformation of hot-mix asphalt-concrete (HMA). Pirabarooban, Zaman, and Tarefder (2003) developed an elasto-viscoelastic creep model that represents the time-dependency of asphalt mixtures to evaluate their rutting resistance. Huang (1995) showed that nonlinear viscoelastic and viscoplastic models are capable of capturing the pavement response under different temperatures. A nonlinear time-hardening creep model to simulate a large number of loading cycles was proposed by Huang (1995) and further improved by Hua (2000) and Al-Qadi et al. (2009). Studies by Fang et al. (2004) and Al-Qadi et al. (2009) showed the effectiveness of using a nonlinear time-hardening creep model to compute permanent deformations. Leonardi (2015) modelled runway pavement using nonlinear time-hardening creep model for HMA surface layer and a linear elastic material model for the granular layers, the results showed good correlation between simulation results and the field measurements. Varma and Kutay (2016) developed an analytical solution and compared it to the FE solution that used viscoelastic material for the AC layer and nonlinear material model for the unbounded road base and subgrade soils. Mulungye, Owende, and Mellon (2007) simulated a road structure using two (one for longitudinal, one for transversal direction) 2D FE models with viscoelastic material models.

Additionally, there is a clear need for new and open computational modeling and simulation techniques and approaches as noted by the roadmap issued by the European Materials Modeling Council (The European Materials Modeling Council, 2018). Moreover, need for new modelling software particularly for engineering applications, such as uncertainty quantification, risk analysis and decision in engineering, has been recognized by the Council of the European Union in its decision that established the Horizon 2020 program (European Commission, 2013).

\section{Methods}

\subsection{Determination of elastic and fatigue material properties}

Initial elastic and fatigue properties of asphalt concrete materials (AC11 and SMA11) were determined by 4-point bending fatigue test method according to EN 12697-24 Annex D standard using Large Hydraulic Four Point Bending Machine by Cooper 


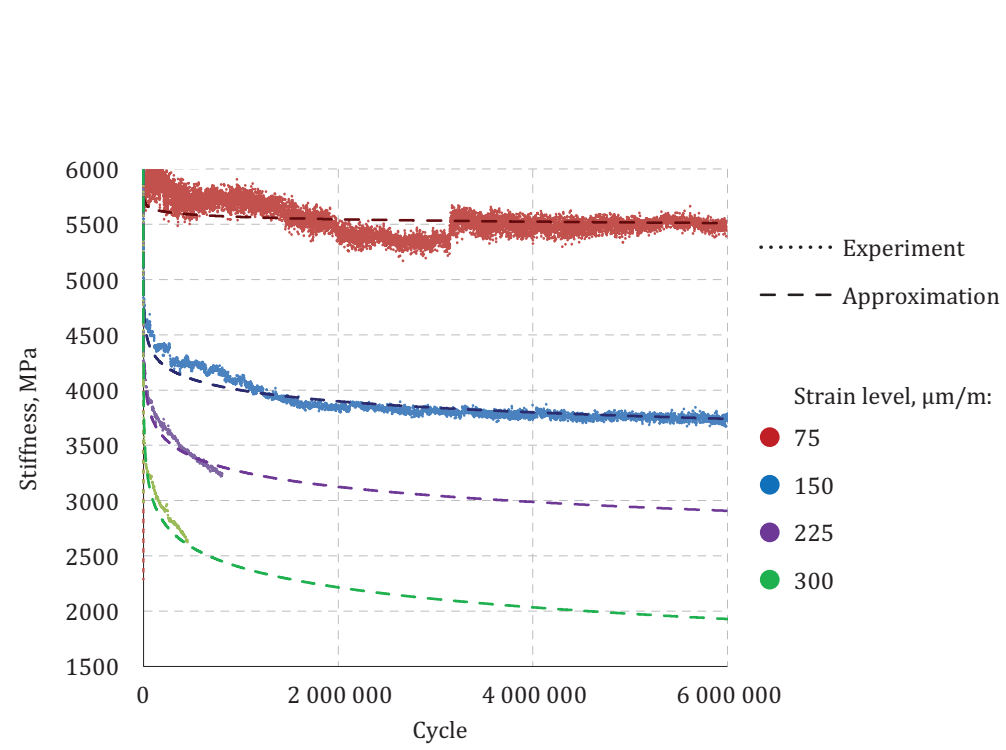

Peteris Skels,

Viktors Haritonovs,

Pavel Akishin,

Andris Freimanis

Study

of Asphalt-Concrete Pavement Fatigue

Modeling

Figure 1. Fatigue curves of AC11

Technologies (experimental equipment). Specimens with dimensions $380 \times 50 \times 50 \mathrm{~mm}$ were tested to 4-point-bending with effective length of $355.5 \mathrm{~mm}$. Symmetric bending at frequency of $10 \mathrm{~Hz}$ and constant strain amplitude of 75, 150, 225 and $300 \mu \mathrm{m} / \mathrm{m}$ (for AC11), and 150, 250, 300, 350 and $450 \mu \mathrm{m} / \mathrm{m}$ (for SMA11) was applied to determine dependences of materials stiffness modulus on the loading cycles. The obtained dependences are presented in Figure 1 and Figure 2 for AC11 and SMA11, respectively.

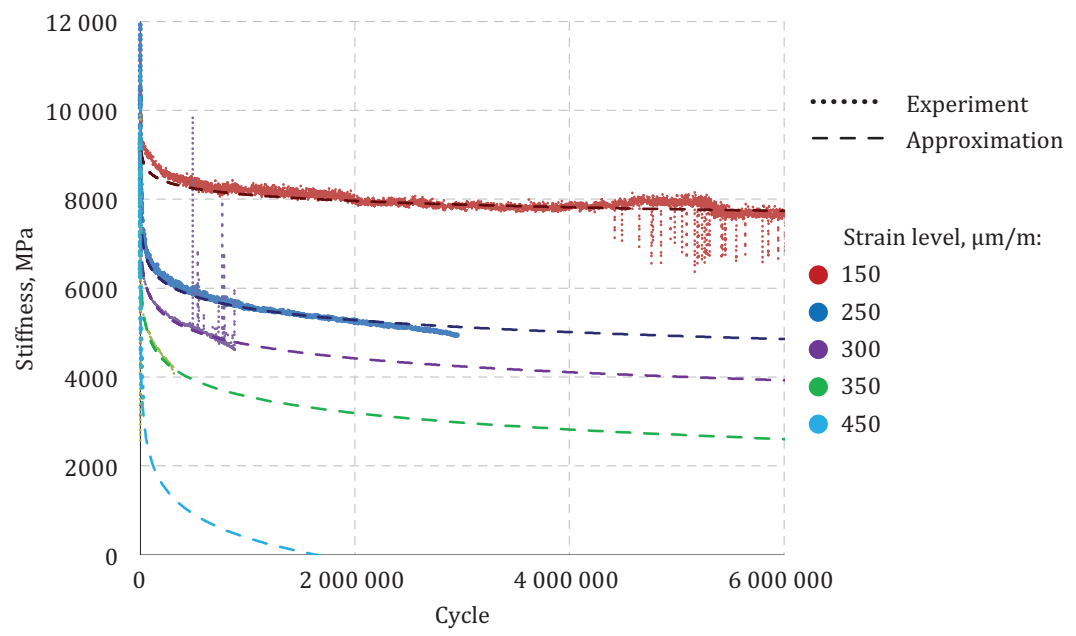

Figure 2. Fatigue curves of SMA11 
Experimentally obtained fatigue curves were approximated for further use in the numerical model. Logarithmic equation was taken for approximation of fatigue curves for both asphalt-concrete materials:

$$
E=E_{0}-k \sum \ln (N)
$$

where $E_{0}$ is initial stiffness modulus, $N$ is cycle number, $k$ is regression coefficient.

Coefficient of approximation function $E_{0}$ and $k$ for each experiment were obtained by regression analysis applying the least squares method:

$$
\Delta=\sum_{i=1}^{n}\left(E_{n}^{e x p}-E_{n}^{\bmod }\right)^{2} \rightarrow \min ,
$$

where $n$ is the number of sampling points.

For the initial regression analysis, both $E_{0}$ and $k$ were taken as variable parameters. The obtained values of coefficients are presented in Table 1 . Then the average value of $E_{0}$ for each material was set as a

\begin{tabular}{|c|c|c|c|c|c|c|c|}
\hline \multicolumn{4}{|c|}{ AC11 } & \multicolumn{4}{|c|}{ SMA11 } \\
\hline $\begin{array}{l}\text { Strain, } \\
\mu \mathrm{m} / \mathrm{m}\end{array}$ & $\begin{array}{l}E_{0} \\
\mathrm{MPa}\end{array}$ & $k$ & $\Delta$ & $\begin{array}{l}\text { Strain, } \\
\mu \mathrm{m} / \mathrm{m}\end{array}$ & $\begin{array}{c}E_{0} \\
\mathrm{MPa}\end{array}$ & $k$ & $\Delta$ \\
\hline 75 & 6793 & 86.0 & 263165146 & 150 & 11531 & 244.6 & 546586512 \\
\hline 150 & 6173 & 156.7 & 48975287 & 250 & 11822 & 454.3 & 359087300 \\
\hline 225 & 5675 & 170.6 & 29292093 & 300 & 10893 & 445.8 & 120915060 \\
\hline 300 & 5334 & 199.0 & 44867956 & 350 & 10507 & 491.4 & 300096292 \\
\hline \multirow[t]{2}{*}{ Average } & 5994 & & & 450 & 9862 & 597.5 & 43761312 \\
\hline & & & & Average & 10923 & & \\
\hline
\end{tabular}

Table 1. Results of the initial regression analysis

\begin{tabular}{|c|c|c|c|c|c|c|c|}
\hline \multicolumn{4}{|c|}{$\mathrm{AC} 11$} & \multicolumn{4}{|c|}{ SMA11 } \\
\hline $\begin{array}{l}\text { Strain, } \\
\mu \mathrm{m} / \mathrm{m}\end{array}$ & $\begin{array}{l}E_{0} \\
\mathrm{MPa}\end{array}$ & $k$ & $\Delta$ & $\begin{array}{l}\text { Strain, } \\
\mu \mathrm{m} / \mathrm{m}\end{array}$ & $\begin{array}{c}E_{0} \\
\mathrm{MPa}\end{array}$ & $k$ & $\Delta$ \\
\hline 75 & \multirow{4}{*}{5994} & 30.9 & 440396070 & 150 & \multirow{5}{*}{10923} & 204.1 & 662290714 \\
\hline 150 & & 144.4 & 57852779 & 250 & & 388.9 & 553748846 \\
\hline 225 & & 197.8 & 48044398 & 300 & & 448.2 & 121085953 \\
\hline \multirow[t]{2}{*}{300} & & 260.5 & 115050404 & 350 & & 533.0 & 225141135 \\
\hline & & & & 450 & & 763.3 & 96721973 \\
\hline
\end{tabular}

Table 2. Results of the regression analysis with fixed initial stiffness 
constant coefficient and the regression analysis was repeated. Results of this analysis are presented in Table 2 and Figures 1 and 2 together with the experimentally obtained curves.

\subsection{Model description}

A four-layer road structure consisting of the bound surface (SMA11, $3 \mathrm{~cm}$ ), bound base layer (AC11, $6 \mathrm{~cm}$ ), subbase layer (gravel, $15 \mathrm{~cm}$ ) and subgrade (sand) was considered in this research. Elastic material properties are presented in Table 3. Time-depending load with the maximum value of $5 \mathrm{t}$ and frequency of $10 \mathrm{~Hz}$ simulating load from truck wheel was applied through a circular metal plate with dimeter of $30 \mathrm{~cm}$. The profile of the corresponding surface load in time domain is presented in Figure 3, and the scheme of the considered domain - in Figure 4 .

Commercial finite element software ANSYS Mechanical was used to build a 2-D numerical model according to the scheme presented in Figure 4. 13148 Plane182 elements defined by four nodes having 2 translational degrees of freedom at each node with characteristic size

Table 3. Material properties

\begin{tabular}{crcc}
\hline Layer & $\boldsymbol{E}, \mathbf{M P a}$ & $\boldsymbol{\eta}$ & $\boldsymbol{\rho}, \mathbf{k g} / \mathbf{m}^{\mathbf{3}}$ \\
\hline SMA11 & $11000^{*}$ & 0.35 & 2420 \\
\hline AC11 & $6000^{*}$ & 0.35 & 2300 \\
\hline gravel & 450 & 0.27 & 2600 \\
\hline sand & 230 & 0.3 & 2000 \\
\hline
\end{tabular}

* initial value of stiffness modulus

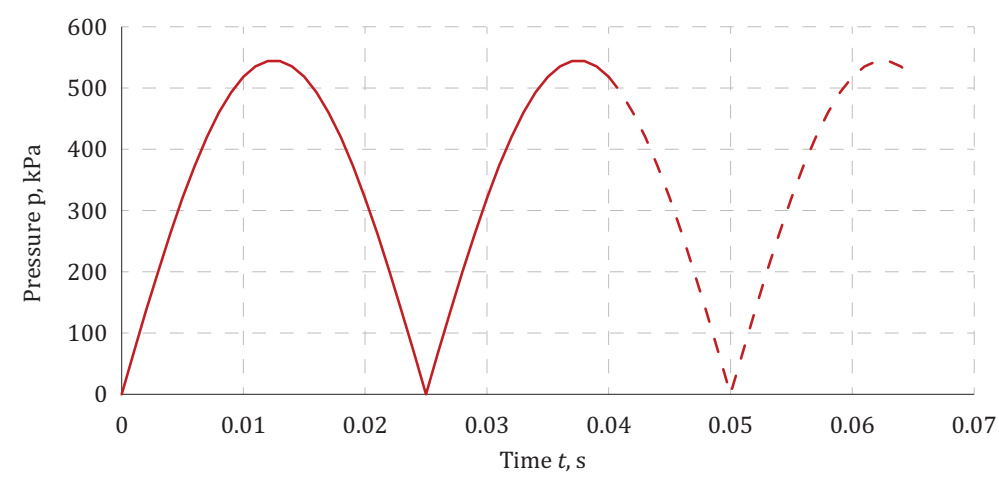

Figure 3. Time-depending surface load
Study

of Asphalt-Concrete Pavement Fatigue Modeling 


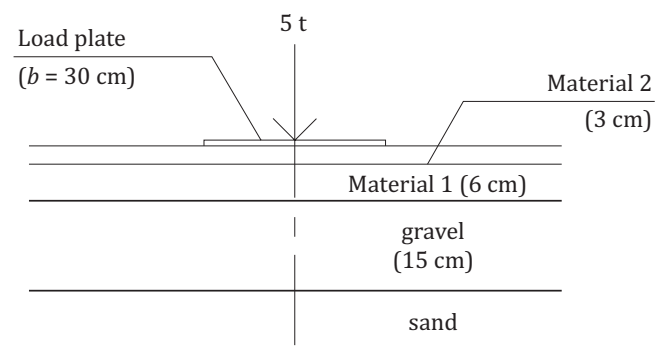

Figure 4. Scheme of the road structure

of 1 to $6.5 \mathrm{~cm}$ depending on element location (smaller elements were used closer to load attaching place) were used to represent all layers of the road structure. A single layer of INFIN257 elements located at the sides and the bottom of the finite simulation domain was used to represent infinity domain. This was done to avoid non-physical reflections of the elastic waves caused by time-dependent external load from the boundaries of the finite simulation domain obtained in the transient analysis of the structure and presented in Figure 5.

As mention before, the transient analysis was used to simulate time-dependent behaviour of the structure. The following procedure presented in Figure 6 have been developed and successfully applied to simulate fatigue of the asphalt concrete materials of two upper layers of the road structure. Initially, elastic properties of these materials were set as constants presented in Table 4 and no fatigue model was applied. After calculation of several loading cycles necessary to obtain steady amplitudes of displacements (Figure 5) and, accordingly, strains, the solution was stopped and the amplitude values of strain intensity in each element were acquired. These values were used to match the fatigue models for finite elements. It is assumed that

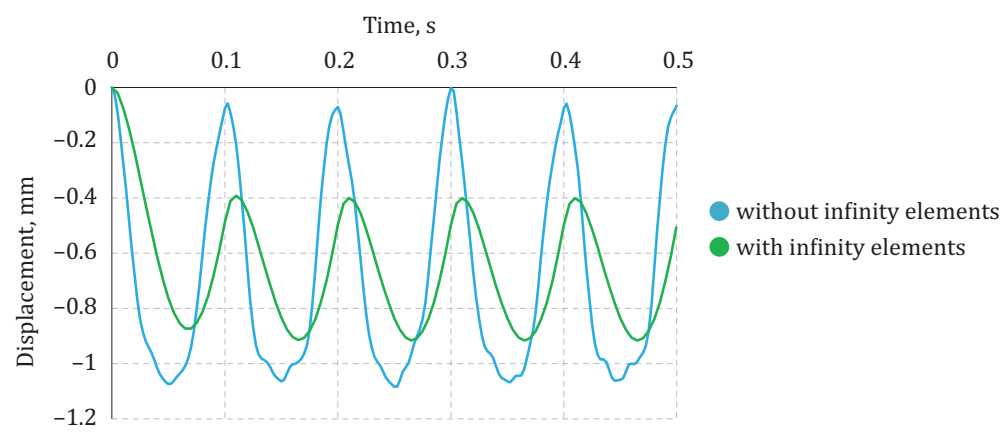

Figure 5. Dependence of the vertical displacements on time 
Table 4. Use of experimentally applied fatigue models

\begin{tabular}{cccc}
\hline & AC11 & \multicolumn{2}{c}{ SMA11 } \\
\hline $\begin{array}{c}\text { Strain intensity in } \\
\text { the finite element, } \\
\mu \mathrm{m} / \mathrm{m}\end{array}$ & $\begin{array}{c}\text { Fatigue model } \\
\text { experimentally obtained } \\
\text { for strain, } \boldsymbol{\mu m} / \mathbf{m}\end{array}$ & $\begin{array}{c}\text { Strain intensity } \\
\text { in the finite } \\
\text { element, } \boldsymbol{\mu m} / \mathbf{m}\end{array}$ & $\begin{array}{c}\text { Fatigue model } \\
\text { experimentally obtained } \\
\text { for strain, } \boldsymbol{\mu m} / \mathbf{m}\end{array}$ \\
\hline$<50$ & no fatigue & $<50$ & no fatigue \\
\hline $50 \ldots 112.5$ & 75 & $50 \ldots 200$ & 150 \\
\hline $112.5 \ldots 187.5$ & 150 & $200 \ldots 275$ & 250 \\
\hline $187.5 \ldots 262.5$ & 225 & $275 \ldots 325$ & 300 \\
\hline$>262.5$ & 300 & $325 \ldots 375$ & 350 \\
\hline & & $>375$ & 450 \\
\hline
\end{tabular}

no fatigue behaviour is observed in the element if strain is less than $50 \mu \mathrm{m} / \mathrm{m}$. For greater values of strain experimentally obtained fatigue models were applied according to Table 4. After change of material models the solution was continued. Since strains in the elements increase over time due to decrease of elastic properties caused by fatigue, it is possible that after some time it is necessary to change fatigue model for some elements. Thus, the procedure that consists of interruption of solution, analysis of the strain level in the elements and material model change with consequent continuation of the solution was repeated during the simulation.

In order to evaluate the effect of this simulation with progressive change of fatigue models, a simpler algorithm was utilized. Only initial

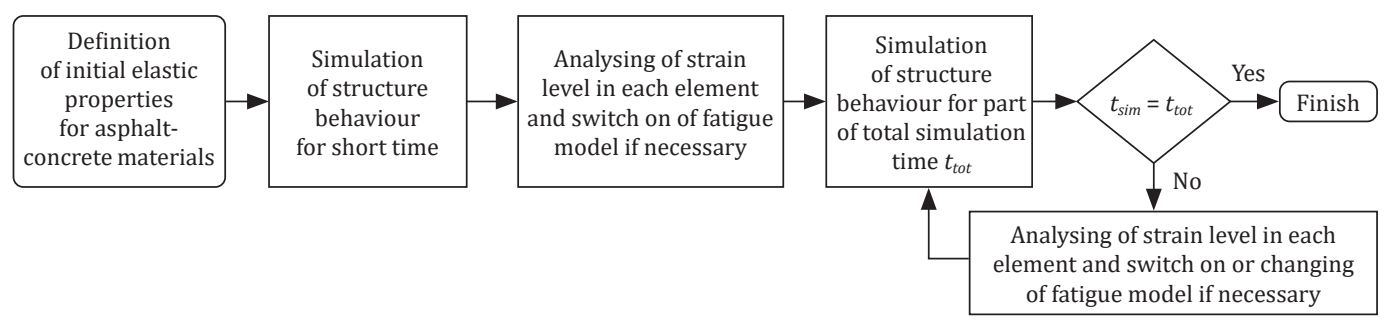

Figure 6. Simulation procedure for fatigue behaviour

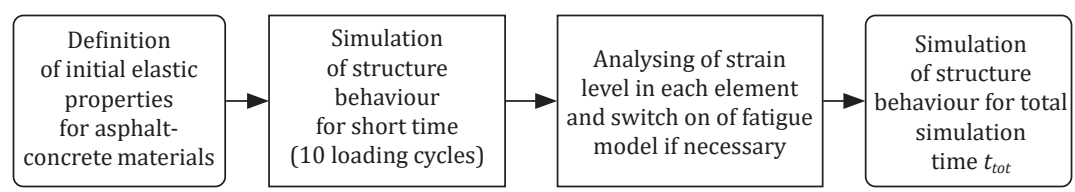

Figure 7. Simplified simulation procedure 
definition of fatigue models after obtaining the steady displacement amplitudes, was used (Figure 7).

Since transient analysis of multi-cycle loading of the structure is a very time and memory consuming process, the degradation of material stiffness properties depending on the number of loading cycles was accelerated 1000 times. It means that one simulated loading cycle is equivalent to 1000 loading cycles in reality. In this case, the previously developed material models (Eq. (1)) with coefficients presented in Table 1 could be used in a slightly modified form as presented in Eq. (3).

$$
E=E_{0}-k \sum \ln (1000 N)
$$

\section{Results and discussion}

Simulation results obtained by full and simplified (Figure 8) procedures showed considerable difference. As it is shown in Figure 8 , increase of the point located at the top of the road structure under the centre of the loading plate, vertical displacement due to fatigue of asphalt concrete materials obtained by the full simulation procedure is $0.032 \mathrm{~mm}$ after 6 million loading cycles. The value obtained by the simplified procedure is $0.017 \mathrm{~mm}$ or 1.9 times smaller. Dependences of absolute values of strains in vertical and horizontal directions obtained by both simulation procedures in the point located between Material 2 and Material 1 under the centre of the loading plate are presented in Figure 9. Smooth and slow increase of strains caused by fatigue behaviour according to the once defined fatigue model is observed in case of calculation by the simplified procedure. The

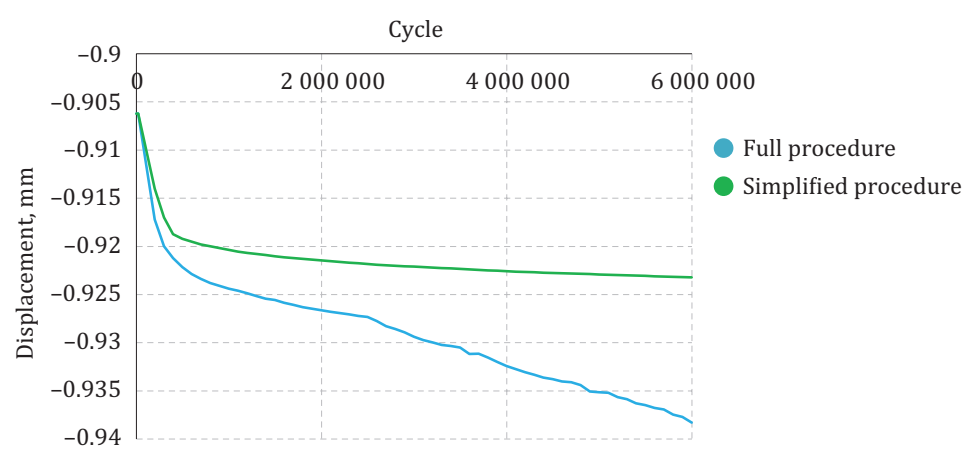

Figure 8. Dependence of vertical displacement on loading cycles 


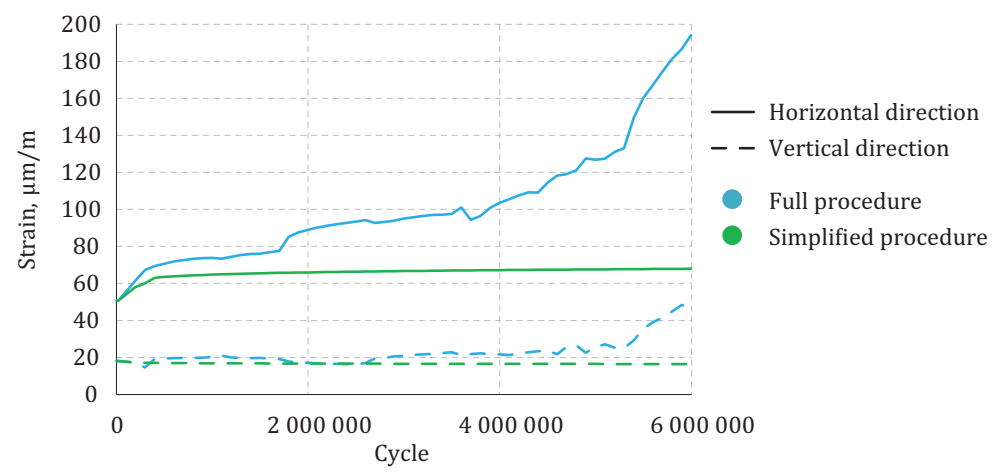

Study

of Asphalt-Concrete Pavement Fatigue Modeling

Figure 9. Dependence of strains on loading cycles

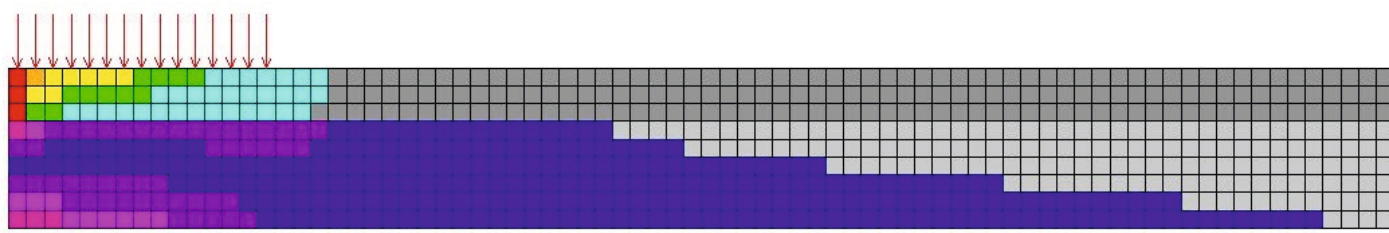

Full simulation procedure

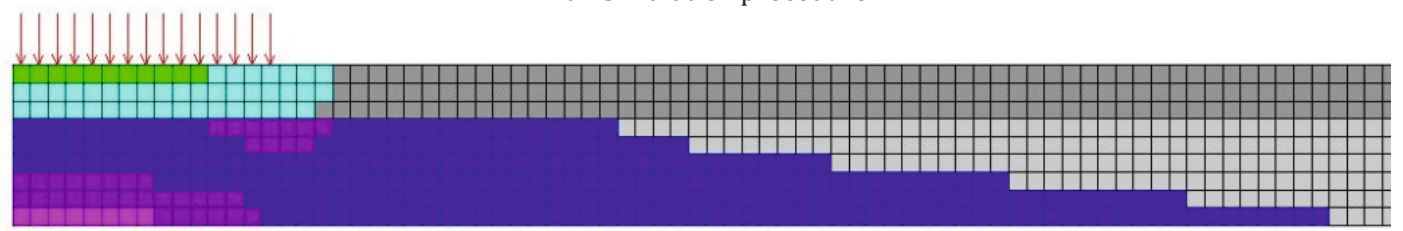

Simplified simulation procedure

\begin{tabular}{l|l} 
Material 1 & $<50 \mu \mathrm{m} / \mathrm{m}$ \\
& $50 \ldots 112.5 \mu \mathrm{m} / \mathrm{m}$ \\
& \\
& $112.5 \ldots 187.5 \mu \mathrm{m} / \mathrm{m}$ \\
& $187.5 \ldots 262.5 \mu \mathrm{m} / \mathrm{m}$ \\
& $>262.5 \mu \mathrm{m} / \mathrm{m}$
\end{tabular}

Material 2

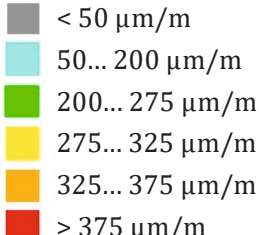

Figure 10. Distribution of fatigue models after 6000000 loading cycles

curves obtained by full simulation procedure are considerably more irregular and the values of strains are greater in comparison with those obtained by the simplified procedure. This phenomenon is explained by progressive change of fatigue models during simulation. Fatigue models applied after 6 million loading cycles are presented in Figure 10. 


\section{Conclusions}

The pavement structural fatigue material model has been presented in this study. The transient analysis has been used to simulate timedependent behaviour of the structure - rapid procedure has been developed and successfully applied to simulate fatigue of the asphalt concrete materials of two upper layers of the road structure.

Elastic properties of these materials initially obtained in the course of laboratory fatigue tests were successfully integrated in this material model.

The boundary conditions are used to represent infinity domain. This is done to avoid non-physical reflections of the elastic waves caused by time-dependent external load from the boundaries of the finite simulation domain obtained in the transient analysis of the structure.

Material models in this procedure were changes and the solution of the task was continued. Since strains in the elements increase over time due to the decrease of elastic properties caused by fatigue, it is possible that after some time it is necessary to change the fatigue model for some elements. Thus, the procedure that comprised interruption of solution, analysis of strain level in the elements and material model change with consequent continuation of the solution was repeated during the simulation.

In order to evaluate the effect of this simulation with progressive change of fatigue models, a simpler algorithm with only initial definition of fatigue models was tried. However, since the curves obtained by full simulation procedure were considerably more irregular and the values of strains were greater in comparison with those obtained by the simplified procedure, it is clear that the full procedure has to be used.

\section{Funding}

This work has been supported by the European Regional Development Fund Project No. 1.1.1.1/16/A/072. 


\section{REFERENCES}

Al-Qadi, I. L., Yoo, P. J., Elseifi, M. A., \& Nelson, S. (2009). Creep Behavior of Hot-Mix Asphalt due to Heavy Vehicular Tire Loading. Journal of Engineering Mechanics, 135(11), 1265-1273. https://doi.org/10.1061/(ASCE)0733-9399(2009)135:11(1265)

Elseifi, M. A., Al-Qadi, I. L., \& Yoo, P. J. (2006). Viscoelastic Modeling and Field Validation of Flexible Pavements. Journal of Engineering Mechanics, 132(2), 172-178. https://doi.org/10.1061/(ASCE)0733-9399(2006)132:2(172)

Erlingsson, S. (2002). 3-D Fe Analyses of Test Road Structures - Comparison with Measurements. Proceedings of the 6th International Conference on The Bearing Capacity of Roads and Airfields, 145-157.

European Commission. (2013). Council Decision of 3 December 2013 establishing the specific programme implementing Horizon 2020 - the Framework Programme for Research and Innovation (2014-2020) and repealing Decisions 2006/971/EC, 2006/972/EC, 2006/973/EC, 2006/974/ EC and 2006/975/EC. Official Journal of the European Union. Retrieved from http://eur-lex.europa.eu/legal-content/EN/TXT/PDF/?uri=CELEX:32013D07 43\&qid=1455193076073\&from $=\mathrm{EN}$

Fang, H., Haddock, J. E., White, T. D., \& Hand, A. J. (2004). On the characterization of flexible pavement rutting using creep model-based finite element analysis. Finite Elements in Analysis and Design, 41(1), 49-73. https://doi.org/10.1016/j.finel.2004.03.002

Hua, J. (2000). Finite element modeling and analysis of accelerated pavement testing devices and rutting phenomenon. Doctoral dissertation, Purdue University. Retrieved from https://docs.lib.purdue.edu/dissertations/AAI3020244/

Huang, H. (1995). Analysis of accelerated pavement tests and finite element modeling of rutting phenomenon. Retrieved from http://docs.lib.purdue.edu/dissertations/AAI9601511/

Kim, Y. R. (2000). Assessing Pavement Layer Condition Using Deflection Data. Project information, Project No 10-48. Transportation Research Board.

Kutay, M. E., Chatti, K., \& Lei, L. (2011). Backcalculation of Dynamic Modulus Mastercurve from Falling Weight Deflectometer Surface Deflections. Journal of the Transportation Research Board, 2227(1), 87-96. https://doi.org/10.3141/2227-10

Leonardi, G. (2015). Finite element analysis for airfield asphalt pavements rutting prediction. Bulletin of the Polish Academy of Sciences: Technical Sciences, 63(2), 397-403. https://doi.org/10.1515/bpasts-2015-0045

Mulungye, R. M., Owende, P. M. O., \& Mellon, K. (2007). Finite element modelling of flexible pavements on soft soil subgrades. Materials and Design, 28(3), 739-756. https://doi.org/10.1016/j.matdes.2005.12.006

Onyango, M. A. (2009). Verification of Mechanistic Prediction Models for Permanent Deformation in Asphalt Mixes Using Accelerated Pavement Testing. An Abstract of a Dissertation, Kansas State University. 
Pirabarooban, S., Zaman, M., \& Tarefder, R. A. (2003). Evaluation Of Rutting Potential In Asphalt Mixes Using Finite Element Modeling. The Transportation Factor 2003. Annual Conference and Exhibition of the Transportation Association of Canada. (Congres et Exposition Annuels de l'Association Des Transport Du Canada), 17. Retrieved from http://trid.trb.org/view.aspx?id=700216

Schapery, R. A. (1969). On the characterization of nonlinear viscoelastic materials. Polymer Engineering and Science, 9(4), 295-310. https://doi.org/10.1002/pen.760090410

Schapery, R. A. (1974). Viscoelastic behavior and analysis of composite materials. Mechanics of Composite Materials. (A 75-24868 10-39) Academic Press, Inc. (pp. 85-168).

The European Materials Modeling Council. (2018). The EMMC RoadMap 2018 for Materials Modelling and Informatics. Retrieved from https:/emmc.info/ wp-content/uploads/2018/09/EMMC_Roadmap2018V5a-del.pdf

Vanelstraete, A. \& Francken L. (Eds). (2014). Prevention of Reflective Cracking in Pavements. CRC Press. https://doi.org/10.1201/9781482294996

Varma, S., \& Kutay, M. E. (2016). Viscoelastic Nonlinear Multilayered Model for Asphalt Pavements. Journal of Engineering Mechanics, 142(7). https://doi.org/10.1061/(ASCE)EM.1943-7889.0001095

Yin, H., Stoffels, S., \& Solaimanian, M. (2008). Optimization of Asphalt Pavement Modeling based on the Global-Local 3D FEM Approach. Road Materials and Pavement Design, 9(2), 345-355. https://doi.org/10.1080/14680629.2008.9690122

Zaghloul, S. M., \& White, T. (1993). Use of a Three-Dimensional, Dynamic Finite Element Program For Analysis of Flexible Pavement. Transportation Research Record, 1388, 60-69. Retrieved from http://onlinepubs.trb.org/Onlinepubs/trr/1993/1388/1388-008.pdf

Zaghloul, S. M. (1993). Non-linear dynamic analysis of flexible and rigid pavements. Doctoral dissertation, Purdue University. Retrieved from https://docs.lib.purdue.edu/dissertations/AAI9334449/ 